\title{
LXIII. Facts upon which to found a history of cobalt and nickel. Extracted by M. Chevreuil
}

\section{Proust}

To cite this article: M. Proust (1808) LXIII. Facts upon which to found a history of cobalt and nickel. Extracted by M. Chevreuil , Philosophical Magazine Series 1, 30:120, 337-347, DOI: $10.1080 / 14786440808563828$

To link to this article: http://dx.doi.org/10.1080/14786440808563828

曲 Published online: 18 May 2009.

Submit your article to this journal

Џ Article views: 3

Q View related articles $₫$ 
are covered with the cactus opuntia. The most common pot-herbs, however, are alone cultivated in them. In some 1 have seen the carica papaya, the melia azedarach, the $b a$ nanier, and the geranium roseum and zonale.

We meet with very few people in the streets, and the in habitants seem to be extremely indulent. There are only five or six shops in the town, where spices, trinkets, and cloths, are sold at a very high price. The Americans import into the place planks, maize, flour, butter, and some other provisions, for which they receive ready money. The money of the couniry is the heavy piaster.

They estimate the population of the Bermudas at eight or nine thousand souls. I do not know the proportion of whites to negroes, but the latter are said to be more numerous. The lower classes are accused of misleading ships in stormy weather, in order to pillage those who have the misfortune to be thrown on their shores; and the Bermudian pirates have always been proverbial for their barbarity.

These islands are said to be very healthy; which cannot be doubted from their situation.

LXIII. Facts upon which to found a History of Colalt and Nickel. By M. Proust. Extracted ly M. Chevreuil**

$\mathrm{T}$ HE sulphuric, muriatic, and nitric acids oxidize metals in the same manner. There is a disengagement of hydrogen with the first two.

Sulphates.-Of these there are two; the one simple, and the other tripled by some neutral salt with a base of potash or ammonia.

1st. The simple sulphate has a slightly pungent taste, a little bitter, and somewhat metallic. Its crystals, not voluminous, are heaped up sections of irregular octaëdrons : they are of a gooseberry red, unalterable in the air ; they lose 42 hundredth parts of water upon distillation;

- From Annales de Chimis, tom. lx. p. 280.

Vol, 30. No. 120. May 1808 . 
they are then red coloured and opaque. In this state they can support a red heat without being decomposed, except in those points at which they touch the retort.

2d. When we mix sulpbate of potash with the foregoing, we obtain more voluminous crystals, which are rhomboidal cubes. This triple salt is less soluble than the simple; it only loses 0.26 of water upon distillation.

Carlonate.-The carbonate of potash 'gives from 0.40 to 0.42 of carbonate of cobalt with the simple sulphate. An excess of alkali dissolves a great part of the precipitate. Ebullition and cold water decompose this solution.

Oxide at the minimum. -100 parts of carbonate leave, after the separation of the water and carbonic acid, from 0.60 to 0.62 of greenish gray oxide. In order to have it very pure, we must charge the retorts as full as possible, and heat them gradually. Without these precautions, we obtain an oxide mixed with oxide at the maximum, which, in this case, gives oxygenated gas with the muriatic acid, while that which is pure does not give an atom of it.

The gray oxide is dissolved with effervescence in the nitric acid, without giving nitrous gas : when heated in the open air, it becomes black immediately. We easily discover an oxide, some parts of which are raised to the maximum by the application of a weak acid, which dissolves only the ninor oxide. Ammonia operates the same separation as Thenard remarked.

Oxide by Precipitation.-1st. Some drops of nitrate of cobalt, poured into boiling water with a little potash in it, give a blue precipitate, which at last becomes red if the ebullition be continued : in this case a hydrate is formed!

2d. If we employ alkalized water cold, the blue precipitate is formed; but in place of making a hydrate it passes to the green, without the contact of the air being able to obscure its shade: it preserves this colour after being dried.

3d. If we boil this green precipitate, while it is fresh, in water with a little potash, it becomes a reddish gray, and does not change any inore.

The weak acids, vinegar for instance, dissolve the first precipitate 
precipitate totally: applied to the other two, they separate black oxide from them. Lastly, the blue oxide does not give any gas with the muriatic acid, while the green does.

From this we must conclude, that the blue oxide is oxygenated at the expense of the air contained in cold liquids, and that the green oxide is a mixture of blue oxide and black oxide. M. Proust thinks nevertheless, that there is something more than a simple mixture; for the blue and black colours would not give this shade of grass green, which distinguishes it from every other oxide. Nothing but a true combination can yield a colour foreign to that of its components, and hinder the action of the air from elevating to the maximum the portion of blue oxide which forms part of the green precipitate. In order to oxidize this precipitate completely, we must dry it by means of heat, as Thenard has shown.

The rcddish gray precipitate, in the third experiment, is a mixture of hydrate and black oxide.

It is only the minimum oxide that can he combined with the acids : the green oxide is never obtained from any solution, and cannot become the base of any saline combination.

Ammonia and Oxide of Cobalt.-The gray oxide put into a well-closed flask, along with ammonia, communicates to it a slight red colour, which does not become higher, however long the flask is kept : this oxide is therefore but very difficultly soluble in ammonia. But if the Hask remain uncorked the ammonia is very quickly coloured, because it attracts carbonic acid from the air. We may operate this solution in a very short time, by placing the flask in a large bason, in which we put a salt of carbonic acid.

If we only saturate the ammonia with acid, the solution is that of the oxide in the carbonate of ammonia. If we continue to make the carbonic acid pass, we obtain a solution of carbonate of colalt in the carlonate of ammonia. This solution, when kept in a flask full and corked, deposits crystals of metallic carbonate; it abandons a part of them by the addition of water : an excess of volatile alkali redissolves this precipitate. We may make this solution very speedily, by throwing carbonate of cobalt into carbonate of ammonia. 
If we put pure ammonia upon carbonate of cobalt in ex: cess, this alters the case completely. The carbonate of $\mathrm{co}-$ balt is divided into two parts : the one yields its acid to the ammonia and becomes hydrate, which is precipitated to the bottom of the vessel, while the portion not decomposed is dissolved into alkaliue carbonate.

Here wè have already two kinds of ammoniacal solutions of cobalt. There is a third discovered by Tassaert, but in general very little remarked hitherto. We obtain it by putting hydrate well washed, or blue oxide, into a flask full of ammonia and well closed. The solution is made in 24 hours. It is red like the former; but differs from them in this respect, that if we pour a drop of it into boiling water, blue oxide is immediately precipitated: when we operate with cold water we obtain green oxide. If ammonia dissolves the hydrate of cobalt, or the fresh blue oxide, more easily than the gray oxide, it is because the two former are in very minute division.

Distillation of the ammoniacal Solution.-When we distil the solution of carbonated cobalt, carbonate of ammonia passes over; the liquor in the end deposits an oxide at first of a dirty green, but which afterwards becomes black. This is a mixture of gray oxide and black oxide.

How happens this hyper-oxidation? M. Proust merely states the fact, and abstains from explanation where data are wanting.

Hydrate of Colalt. - The crystals of sulphate, or of nitrate, thrown into a flask full of liquid potash, and immediately closed, are there decomposed: a blue precipitate is formed, which passes to the violet, afterwards to the red, by becoming hydrate.

If we boil hydrate with potash, the latter dissolves oxide, and is tinged with a fine blue colour. This solution is decomposed upen the addition of water. In the air the oxide becomes black, and is deposited.

The hydrate is dissolved cold in the carbonate of potash, and tinges it red. The oxide is not dissolved.

The hydrate of cobalt is of the colour of a dead rose leaf : the acids dissolve it with heat, and without effervescence.

The hydrate is not decomposed by ebullition, either in 
pure water or in alkalized water. It loses from 20 to 21 of water by heat, and is reduced to very pure gray oxide.

It keeps very badly under water: when it is in contact with the air it becomes black. The dry bydrate is better preserved, but attracts carbonic acid.

When we throw crystals of sulphate into a tlask full of ammonia and immediately closed, they give a blue precipitate, which does not become red as in the potash. M. Proust asserts that the hydrate is formed, but that it is dissolved in some proportion in ammonia; so that it is the hydrate which colours the solution, and not the simple oxide.

Valuaiion of the Oxygen in the minor Oxide.-100 parts of gray oxide, reduced with proper precautions in a closed crucible, give $83 \frac{x}{2}$ of metallic grains. The quintal of cobalt seems therefore to absorb, 19 of oxygen, in order to become minor oxide.

Major oxide.-If we distil a nitric solution of cobalt, black crusts are deposited upon the sides of the retort, nitrous gas is disengaged, and we obtain from 125 to 126 of black oxide as the residue. Hence we may conclude, that the maximum of the oxidation of the cobalt exists about 25 or 26 in 100 .

This oxide is not dissolved in the nitric and sulphuric acids, except by losing the portion of oxygen which constituted its maximum.

It gives oxygen gas with the muriatic acid.

It is insoluble in ammonia and polash.

The black oxide, heated for half an hour at the bottom of a crucible, again becomes gray oxide by losing its oxygen: we may then tinge the vitrescible matters blue:

Messrs. Proust and Thalaker found the black oxide at Pavias, in a journey to Valentia. It is also found in cobalt ores, which have been called vilreous or llack ores.

The carbonate and hydrate of cobalt is changed into black oxide, by the contact of the oxy-muriatic acid.

The nitrous and sulphurous acids dissolve the black oxide, and form with it nitrate and sulphate at the minimum.

Muriate of Cobalt.-The gray oxide is dissolved with heat in an acid of $15^{\circ}$. The warm or cold solution is of a deep 
blue; it crystallizes easily; the crystals are blue; it is the de-hydrated muriate. As soon as it absorbs humidity it becomes red.

The muriatic acid at $15^{\circ}$ yields a great deal of gas with black oxide. This solution is green while it retains the gas; but as soon as it has lost it, it becomes blue. The blue traits of the muriate of cobalt, dried upon paper, are nothing else than de-hydrated muriate. When they are gieen, it is because the salt still contains muriate of nickel, which tinges it yellow, and forms green with the blue.

Its Distillation.-When brought to a red heat in a luted retort, those parts only which touch the glass are decomposed : the products then are muriatic acid in vapour, mixed with oxygenated acid. The glass is tinged blue. The nondecomposed muriate is sublimed, after being melted in gray flaky flowers; these undergo a kind of condensation, which renders them insoluble in water for at least 12 hours. Latterly, they give a solution of common muriate.

Arsenite and Arseniate. - The arsenite of cobalt is prepared by pouring a solution of cobalt well diluted into a solution of arsenite of potash. We obtain a red precipitate, which preserves this colour upon drying.

Character of the Arsenite.-1st. Heated in a tube closed at one end, it is decomposed; the oxide of arsenic is sublimed, and the glass is tinged blue.

ad. The nitric acid dissolves it, and there is nitrous gas.

3d. The muriatic solution is decomposed by sulphuretted hydrogen, which precipitates orpiment.

4th. Pure potash, with the assistance of heat, sets free the blue oxide.

Arseniate.-We obtain it bv using arseniate of potash in place of arsenite. The precipitate is red, like the arsenite,

Characters.-1st. Heated in the tube, it does nat give any sublimate; it becomes violet, without tingeing the glass.

$2 \mathrm{~d}$. The nitric acid dissolves it without nitrous gas.

3d. Its muriatic solution is not disturbed by the sulphuretted hydrogen until two hours after the nixture.

4th. Pure potash sets free the blue oxide, and is combined with the acid. 
The red efflorescences which we find upon minerals containing cobalt are formed of arseniate. M. Proust found the arsenite in the heart of some pieces only.

Hydro sulphurettcd Oxide. Sulphuret of Colalt.-The gray oxide, the hydrate, and carbonate, take from water the sulphuretted hydrogen, and become hydro-sulphuretted oxide. The latter is not dissolved in ammonia; it gives water and sulphurous acid upon distillation. The remainder is sulphuret.

The oxides when heated with sulphur become sulphuret. Cobalt absorbs 40 per cent. of sulphur. The author has still some doubts upon this subject.

\section{Facts respecting the History of Nickel.}

Nitrate.-100 parts of metal dissolved in the nitric acid, and distilled until perfectly decomposed, leave from 125 to 126 of greenish gray oxide at the minimum. The nitrie acid canuot make this oxide pass to the maximum.

In order to ascertain the purity of the oxide of nickel, we must dissolve it in the muriatic acid and heat it. If it contains a little oxice of cobalt, there will be an extrication of oxygenated muriatic gas : if it be pure, none will be disengaged.

The gray oxide is dissolved in all the acids, and gives the same solutions as the metals.

Nitrate at the minimum.-By iistilling the nitrate of nickel with the same precautions as the nitrate of copper, we obtain, as with the latter, a nitrate with excess of base, which is insoluble in water. 100 parts of nickel give 142 of hi, nitrate: on deducting the 2.5 parts of oxygen absorbed by the metal, we have 17 parts of acid fixed upon this oxide.

100 parts of dry nitrate of nickel gave upon distillation 20 of water, and 25 of oxide : therefore 55 of acid. These proportions are not rigorousiy exact, because the last portions of water are a little acid.

Muriate of Nickel.-This is a granulous crystallization of an apple green, and very deliquescent.

The traces of this salt, when dried upon paper, are yellow.

$$
\text { Y } 4
$$


This muriate loses 55 of water. What remains is a yellow de-hydrated muriate, which again becomes green in the air, by absorbing water.

The de-hydrated muriate, when fire is applied to it, does not melt : those parts only which touch the glass are decomposed : there is then an extrication of simple muriatic acid and oxygenated acid : the salt not decomposed is sublimed under the form of pearl-like flowers of a golden yellow. These flowers in two days absorb humidity, and become green. The muriatic acid dissolves them with difficulty.

100 parts of muriate of nickel gave, by means of carbonate of potash, from 61 to 62 of carbonate; which supposes from 33 to 34 of oxide.

Sulphates of Nickel.-There are two, the one simple and the other potashed. The first crystallizes in hexaëdral prisms terminated by an irregular pyramid ; the second in rhomboidal prisms.

The simple sulphate loses 46 parts out of the 100 of water, The de-hydrated residue again becomes green on absorbing humidity. When strongly heated for an hour, and at a red heat, in a luted retort, it is partly reduced to the state of sulphate with an excess of base : water takes away that part which has not lost its acid.

100 parts of this sulphate gave 64 of carbonate of a clear green.

The potashed sulphate loses $24-100 \mathrm{dth}$ of water. The residue acts like that of the simple sulphate. The potashed sulphate only gives from 27 to 28 of carbonate for 100 .

The two sulphates of nickel are transparent, of a fine emerald green; they are unalterable in the air. M. Proust thinks that the sulphate of potash is united to that of the nickel in a constant proportion.

Extraction of the Nickel on a large Scale.-Let there be an ample solution of ore first calcined, and afterwards vitriolized with the residues of ether. It is requisite to separate the nickel from iron, copper, arsenic, bismuth, and cobalt. The iron is at the maximum: in this state it has little affinity for the acids. We may then precipitate it to 
the state of arseniate, by means of potash, which we must add gradually. Ammonia, or a prussiate, afterwards proves if all the iron has been precipitated.

Into the filtered solution we make a current of sulphuretted hydrogen to pass; the copper, bismuth, and the whole of the arsenic are precipitated in the form of sulphurets.

When the sulphuretted bydrogen occasions no more precipitate, we reduce the liquor in order to crystallize it. The potashed sulphate of nickel, less solub': than the potashed sulphate of cobalt, is the first to crystallize. On repeating the crystallizations, we succeed in separating the two salts: as to the last portions of the salt of nickel, washing them in cold water takes off the sulphate of cobalt they contain.

All these crystallizations require 3 bason of fine silver, if we wish to proceed smoothly.

We ascertain that a salt of nickel is pure, when the precipitate dissolved in ammonia abandons this solvent without our finding any cobalt in it.

When we precipitate a sulphate of nickel, we must not be too sparing of the potash : without this precaution we might run the risk of precipitating sulphate with excess of base; which would alter the purity of the precipitate.

Carbonate of Nickel. -100 parts heated in a retort give from 54 to 65 of greenish gray oxide at the minimum. When we heat it in contact with the air, the oxide is black.

The minor oxide becomes carbonate when exposed to the air.

Hydrate of Nickel. - All the salts of nickel when thrown into boiling potash are changed into green hydrate; boiling does not alter the shade of them. Potash neither dissolves the hydrate nor the oxide of nickel.

The hydrate heated is reduced to gray oxide.

The oxide is in the state of hydrate in the saline com. pinations. The alkalis precipitate it in this state.

Major Oxide of Nickel.-The carbonate and hydrate rise to the maximum, when we put them in contact with the oxygenated muriatic acid. It is more difficult to oxidize the gray oxide. 
The dry major oxide of nickel is black; when in a mass its fracture is vitreous.

This oxide, preserved in ammonia, gives out bubbles, returns to the state of gray oxide, and is dissolved in the alkali.

It gives a considerable quantity of oxygenated acid, with a muriatic acid at $15^{\circ}$. The solution is greenish yellow: crystals are formed upon cooling.

The oxides of nickel are reduced like those of cobalt. They are melted in the same way, with this difference only, that the cobalt gives a larger globule.

This metal has taken a surcharge of sulphur from 46 to 100 ; but the author has still his doubts on this subject.

Arsenite and Arseniate.-They are formed like those of cobalt, and are of a fine apple-green colour. The arsenite heated in the tube loses its colour with water, sets at liberty some white oxide, and passes to the olive-green. Charcoal is necessary in order to take away all the arsenic.

When heated in a platina spoon, the arsenic is speedily dissipated. An oxide at the minimum remains,

The arseniate heated in a gun-barrel loses its colour with water ; becoming of a hyacinth and transparent appearance: but at a red heat it passes to the clear yellow, and remains unalterable.

In the spon the arseniate becomes white, reddens without melting, or emitring the smallest arsenical fumes : we must avoid flame in order to decompose it.

\section{Recapitulution.}

M. Proust concludes from the foregoing facts, and from those he has published in other memoirs, that cobalt, nickel, and most of the other known metals, bave only two degrees of oxidation distinctly marked: he has not asserted, however, that a metal can only absorb two proportions of oxygen : he only says that it is not yet time to admit all the oxides hitherto spoken of, and in which we have neither seen the quantity of oxygen ascertained, nor the combinations which they are susceptible of forming with the acids; and he adds that colour is not a sufficient character by which to distinguish them. 
The mean Motions of the Sun and Moon, Eoc.

There are only two metals which have as yet presented to the author more than two oxidations : these are tin and lead: notwithstanding this, the quantity of oxygen in the oxide of tin (the base of aurum musivum) is not yet known, nor that of the oxide in the nitrate of lead which has been boiled with plates of this metal.

It seems that the different oxides of one and the same metal may be intermediately disaolved, and form true combinations. Thus the green oxide of cobalt is a combination of blue and black oxide.

May not minium be a combination of brown oxide and of oxide at 9 in 100, and analogous to the foregoing?

Finally: all the magnetic ores of iron and the attractable sands are mixtures or combinations of this order: if this were nut the case, what could prevent the minor oxide from rising (1) the maximum? The oxide of the gun-barrel which has served to decompose the water is also in the same case; it is formed of the two oxides.

LXIV. The mean Motions of the Sun and Moon, of the Sun's Perigee, the Moon's Perigee and Node; the Times of their several Revolutions, loth in respect to the Equinox. and to the fixed Stars, and in respect to each other: deduced from the New Talles of the Sun and Moon lately published by the French Board of Longitude. By James Epps, Esq.

$$
\text { To Mr. Tilloch. }
$$

SIR,

SHould you think the enclosed paper deserving a place in your Magazine, it is at your service. It contains the result of very tedious though not difficult calculations; and, as it exhibits an interesting view of the modern solar and lunar astronomy, will, I think, prove acceptable to your astronomical readers.

I am, sir, yours \&c.

No. 4, Commercial Road,

JAMES EpPs.

May 14, 1308. 